\title{
Molecular characterization and immune functional analysis of IRF2 in common carp (Cyprinus carpio L.): different regulatory role in the IFN and NF-KB signalling pathway
}

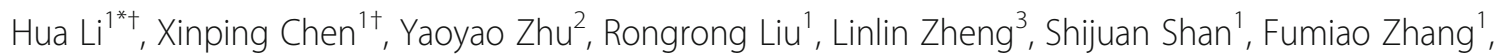
Liguo $\mathrm{An}^{1}$ and Guiwen Yang ${ }^{1 *}$

\begin{abstract}
Background: Interferon regulatory factor 2 (IRF2) is an important transcription factor, which can regulate the IFN response and plays a role in antiviral innate immunity in teleost.

Results: In the present study, the full-length cDNA sequence of IRF2 (CCIRF2) was characterized in common carp (Cyprinus carpio L.), which encoded a protein containing a conserved DNA-binding domain (DBD) and an IRFassociated domain (IAD). Phylogenetic analysis showed that CCIRF2 was most closely related with IRF2 of Ctenopharyngodon idella. CCIRF2 transcripts were detectable in all examined tissues, with higher expression in the gills, spleen and brain. CCIRF2 expression was upregulated in immune-related tissues of common carp upon polyinosinic:polycytidylic acid (poly (I:C)) and Aeromonas hydrophila stimulation and induced by poly (l:C), lipopolysaccharide (LPS), peptidoglycan (PGN) and flagellin in the peripheral blood leucocytes (PBLs) and head kidney leukocytes (HKLs). In addition, overexpression of CCIRF2 decreased the expression of IFN and IFN-stimulated genes (ISGs), and a dual-luciferase reporter assay revealed that CCIRF2 could increase the activation of NF-kB.

Conclusions: These results indicate that CIRF2 participates in antiviral and antibacterial immune response and negatively regulates the IFN response, which provide a new insight into the regulation of IFN system in common carp, and are helpful for the prevention and control of infectious diseases in carp farming.
\end{abstract}

Keywords: Common carp (Cyprinus carpio L.), Interferon regulatory factor 2 (IRF2), Poly (I:C), Aeromonas hydrophila, IFN, NF-KB

\section{Background}

Interferon (IFN) regulatory factors (IRFs) are key transcription factors in vertebrates and invertebrates, which regulate the expression of IFNs and IFN-stimulated genes (ISGs), and perform diverse biological functions in

\footnotetext{
*Correspondence: lihua@sdnu.edu.cn; yanggw@sdnu.edu.cn

${ }^{+} \mathrm{Hua}$ Li and Xinping Chen contributed equally to this work.

'Shandong Provincial Key Laboratory of Animal Resistance Biology, College of Life Sciences, Shandong Normal University, No. 88 East Wenhua Road, Jinan 250014, China

Full list of author information is available at the end of the article
}

innate and adaptive immunity [1]. All IRFs contain a highly conserved DNA-binding domain (DBD) at their $\mathrm{N}$-terminus, which is responsible for binding the IFNstimulated response element (ISRE) in target genes by a helix-turn-helix motif [2]. At the C-terminus is an IRF association domain (IAD), which mediates interactions with several transcription factors and cofactors to form transcriptional complexes [3, 4].

To date, 11 members of the IRF family have been characterized in fish [5], and interferon regulatory factor

C C The Author(s). 2021 Open Access This article is licensed under a Creative Commons Attribution 4.0 International License, which permits use, sharing, adaptation, distribution and reproduction in any medium or format, as long as you give appropriate credit to the original author(s) and the source, provide a link to the Creative Commons licence, and indicate if changes were made. The images or other third party material in this article are included in the article's Creative Commons licence, unless indicated otherwise in a credit line to the material. If material is not included in the article's Creative Commons licence and your intended use is not permitted by statutory regulation or exceeds the permitted use, you will need to obtain permission directly from the copyright holder. To view a copy of this licence, visit http://creativecommons.org/licenses/by/4.0/. The Creative Commons Public Domain Dedication waiver (http://creativecommons.org/publicdomain/zero/1.0/) applies to the data made available in this article, unless otherwise stated in a credit line to the data. 
2 (IRF2) has been characterized in rainbow trout (Oncorhynchus mykiss) [6], mandarin fish (Siniperca chuatsi) [7], snakehead (Channa argus) [8], zebrafish (Dario rerio) [9], stickleback (Gasterosteus aculeatus) [9], orange-spotted grouper (Epinephelus coioides) [10], Atlantic salmon (Salmo salar) [11], paddlefish (Polyodon spathula) [12], miiuy croaker (Miichthys miiuy) [13], grass carp (Ctenopharyngodon idella) [14], blunt snout bream (Megalobrama amblycephala) [15], Atlantic cod (Gadus morhua) [16] and golden pompano (Trachinotus ovatus) [5]. The expression of IRF2 can be upregulated by viral $[5-8,10,12-14,16]$ or bacterial $[5,10,15]$ stimulation in different fish tissues, suggesting that IRF2 plays a role in host antiviral and antibacterial responses.

The IFN response is crucial to the antiviral innate immunity of teleost, which can be regulated by IRF2 in different ways. In zebrafish, the expression level of IFN $\alpha$ is increased by the knockdown of IRF2, which has been shown to negatively regulate IFN $\alpha$ signalling [17]. In Atlantic salmon, IRF2 acts as a negative regulatory factor for IFNa1 by competing with IRF-1 [11]. In grass carp, IRF2 can also bind the promoter of IFN via its DBD and downregulate the transcriptional activity of IFN [14]. However, IRF2 plays a positive role in regulating IFNa3 and IFN $\gamma$ expression in golden pompano $[5,18]$. Interestingly, in large yellow croaker, IRF2 was found to induce IFNd and IFNh promoter activity but inhibit IFNc promoter activity [19].

Common carp (Cyprinus carpio L.) is a pivotal aquaculture fish species widely cultured in Asia and Europe. Several IRFs have been identified from common carp, including IRF1, IRF3, IRF5, IRF7, IRF9 and IRF10 [20-24]. Aeromonas hydrophila is a wellknown fish pathogenic bacterium that can cause infection in a number of fish species [25], including common carp (Cyprinus carpio) [26], goldfish (Carassius auratus auratus) [27], yellow catfish (Pelteobagrus fulvidraco) [28] and channel catfish (Ictalurus punctatus) [29]. Furthermore, fish are becoming more and more susceptible to A. hydrophila because of the increasing intensive rearing methods used in the aquaculture [30]. The previous studies have reported that carp IRFs participated in the immune response against $A$. hydrophila [23]. Thus, in the present study, we identified the full-length cDNA sequence of IRF2 (CcIRF2) in common carp, and investigated its responsiveness to viral and bacterial immune stimulation both in vivo and in vitro. Meanwhile, we determined the roles of CcIRF2 in regulating the IFN response and NF- $\mathrm{KB}$ signalling pathway. The present study will contribute to understand the innate immune system of fish, and is helpful for the prevention and control of infectious diseases in carp farming.

\section{Methods}

\section{Fish feeding and experimental challenge}

Common carp (about $200 \mathrm{~g}$ per fish) used in the study were purchased from a local fish farm in Jinan, China. After maintained in a fish feeding system (Qingdao Aiwen) at $20^{\circ} \mathrm{C}$ for at least one week, 50 fish were anesthetized by immersion in a $100 \mathrm{mg} / \mathrm{l}$ solution of MS222 (Sigma), and then evenly divided into two groups to injected intraperitoneally with $500 \mu \mathrm{l}$ of $2.6 \mathrm{mg} / \mathrm{ml}$ poly (I:C) solution (Sigma) or $4.0 \times 10^{8} / \mathrm{ml}$ Aeromonas hydrophila, which were inactivated with $0.5 \%$ formalin and resuspended in PBS [23, 31, 32]. At 0, 3, 6, 12, 24, 48 and $72 \mathrm{~h}$ post-injection (hpi), three fish were anesthetized and the liver, spleen, head kidney, skin, foregut and hindgut were collected.

\section{Cloning and analysis of the CCIRF2 CDNA}

Total RNA was extracted from head kidney of common carp using TRIzol reagent (TIANGEN), and cDNA was synthesized using a FastQuant RT Kit (TIANGEN). A partial sequence of CcIRF2 was amplified by PCR using the primers IRF2-F/IRF2-R (Table 1), which were designed based on the cDNA sequences of several known fish IRF2. Then, the full-length cDNA sequence was obtained by $3^{\prime}$ - and 5'-Full RACE (rapid amplification of cDNA ends) method (TaKaRa). The domains of the CcIRF2 protein were analysed using Simple Modular Architecture Research Tool (SMART, http://smart.emblheidelberg.de), and multiple sequence alignment and phylogenetic analysis was performed using MEGA 6.0.

\section{Preparation of PBLs and HKLs from common carp}

Peripheral blood leucocytes (PBLs) and head kidney leukocytes (HKLs) of common carp were prepared according to previous studies [23, 33]. In brief, peripheral blood and head kidney cell suspensions were loaded onto freshly prepared 34\%/51\% Percoll (Sigma) density gradients and separated via centrifugation at $650 \mathrm{~g}$ for $30 \mathrm{~min}$. The cells were resuspended and cultivated at $25^{\circ} \mathrm{C}$ in Leibovitz's L- 15 medium with $10 \%$ foetal bovine serum (FBS), $100 \mathrm{UI} / \mathrm{ml}$ penicillin and $100 \mathrm{mg} / \mathrm{ml}$ streptomycin.

\section{Overexpression of CCIRF2 in EPC cells}

The open reading frame (ORF) of CcIRF2 was amplified by PCR using Phusion High-Fidelity DNA polymerase (PrimeSTAR), and purified fragments were ligated into the pcDNA3.1-EGFP vector and transformed into $E$. coli Top10 cells. The overexpression vector was extracted from positive clone using an endotoxin-free plasmid isolation kit (TIANGEN) and verified by sequencing. Epithelioma papulosum cyprini (EPC) cells were cultivated at $25^{\circ} \mathrm{C}$ in M199 medium (HyClone) with $10 \%$ FBS, 100 $\mathrm{U} / \mathrm{ml}$ penicillin and $100 \mu \mathrm{g} / \mathrm{ml}$ streptomycin (Gibco). 
Table 1 Primers used in the present study

\begin{tabular}{|c|c|c|}
\hline Name of primer & Sequence(5'-3') & GenBank accession No. \\
\hline CCIRF2-F & CAGATTCCGTGGATGCATG & \\
\hline CCIRF2-R & GTCTTCATGATGACGCTGG & \\
\hline CIRF2 RT-F & TGGAGCAGAGAGCGATACAGACAG & \\
\hline CCIRF2 RT-R & GCAGTGCCATCCTCACCTTCTTG & \\
\hline CIRF2 ORF-F & CCCAAGCTTATGCCGGTGGAGAGAATGCGT & \\
\hline CCIRF2 ORF-R & TCCCCGCGGGCAAGTCTTGACGGAGGATTTGG & \\
\hline CCS11-F & CCGTGGGTGACATCGTTACA & AB012087 \\
\hline $\operatorname{CCS} 11-\mathrm{R}$ & TCAGGACATTGAACCTCACTGTCT & \\
\hline EPC-IFN-F & CGCTAAGGTGGAGGACCAGGTTA & FN178457 \\
\hline EPC-IFN-R & TTAGGTTCCATTGTGCTGCGTTCA & \\
\hline EPC-PKR-F & TGGAGACTTCGGCCTCGTGACT & KM099176 \\
\hline EPC-PKR-R & TCGCTTGCTCCGGGCTCATGTA & \\
\hline EPC-Viperin-F & AAGACTTCCTGGACCGCCATAAGA & KM099177 \\
\hline EPC-Viperin- $R$ & CCTCTCGGCAATCCAAGAAGCG & \\
\hline EPC-ISG15-F & ACAGTCGGTGAACTCAAGCAAGTC & KM099174 \\
\hline EPC-ISG15-R & CGTAACTGCTGAGGCTTCTGGAAT & \\
\hline EPC-IRF3-F & CGTGTCCACCACATGCTGAAGG & KJ027520 \\
\hline EPC-IRF3-R & ATCCAGAATCCTCCACCAGCTTGT & \\
\hline$E P C-\beta$-actin- $F$ & GCCGTGACCTGACTGACTACCT & KF844250 \\
\hline$E P C-\beta$-actin- $R$ & GCCACATAGCAGAGCTTCTCCTTG & \\
\hline
\end{tabular}

Cells were transfected with pcDNA3.1-EGFP-CcIRF2 using X-tremeGENE HP DNA Transfection Reagent (Roche) at $2 \mu \mathrm{l} /$ well following the manufacturer's instructions.

\section{Real-time PCR analysis}

Real-time PCR was performed with TransStart Tip Green qPCR SuperMix (TransGen) in a Rotor-Gene Q PCR instrument (Qiagen) [23]. The expression levels of all genes were calculated relative to those of the $40 \mathrm{~S}$ ribosomal protein $\mathrm{S} 11$ or the $\beta$-actin gene using the $2^{(-\Delta \Delta \mathrm{Ct})}$ method. The primers used are listed in Table 1.

\section{Dual-luciferase reporter assays}

The effects of CcIRF2 on the activation of NF- $\kappa B$ were performed using Dual-luciferase reporter assays. The $293 \mathrm{~T}$ cells were cultivated at $37^{\circ} \mathrm{C}$ in DMEM medium (HyClone) with $10 \%$ FBS, $100 \mathrm{U} / \mathrm{ml}$ penicillin and $100 \mu \mathrm{g} / \mathrm{ml}$ streptomycin (Gibco), and transfected with reporter gene plasmids, pGL-NF-kB-luc and pGLRenilla-luc, and the pcDNA3.1-EGFP-CcIRF2 vector using Lipofectamine 2000 (Invitrogen). $48 \mathrm{~h}$ after transfection, the Dual-Glo ${ }^{\circ}$ Luciferase Reagent (Promega) was used to measure firefly and Renilla luciferase activity according to the manufacturer's instructions.

\section{Statistical analysis}

Differences significance analysis were performed using one-way analysis of variance (ANOVA) or T-test in GraphPad Prism 6. All the data were homogeneous and normal, and $P<0.05$ was considered as significative.

\section{Results}

Cloning and characterization of CCIRF2

The full-length cDNA of CcIRF2 (GenBank accession No. MW559072) consists of 1916 bp, including an ORF of $1005 \mathrm{bp}$ that translates into a 334-amino acid putative peptide. The 5'and 3'-untranslated region (UTR) of the cDNA is $118 \mathrm{bp}$ and $793 \mathrm{bp}$, respectively, and an mRNA instability motif $\left({ }^{1861}\right.$ AATAA $\left.^{1865}\right)$ is contained in the $3^{\prime}$ UTR. The predicted CCIRF2 protein contains a DBD (M1-S115) and an IAD (E211-F265) domain, with six tryptophan residues (Trp11, 26, 38, 46, 58 and 76) and a nuclear localization signal (NLS) in the DBD.

Multiple sequence alignment revealed that IRF2 amino acids sequences were conserved in all vertebrates, and significant homology was found in DBD (Fig. 1). The phylogenetic tree including IRF2 sequences from all known species was constructed using the neighbourjoining method, which was divided into multiple branches, and CcIRF2 was most closely related with IRF2 of C. idella (Fig. 2). 


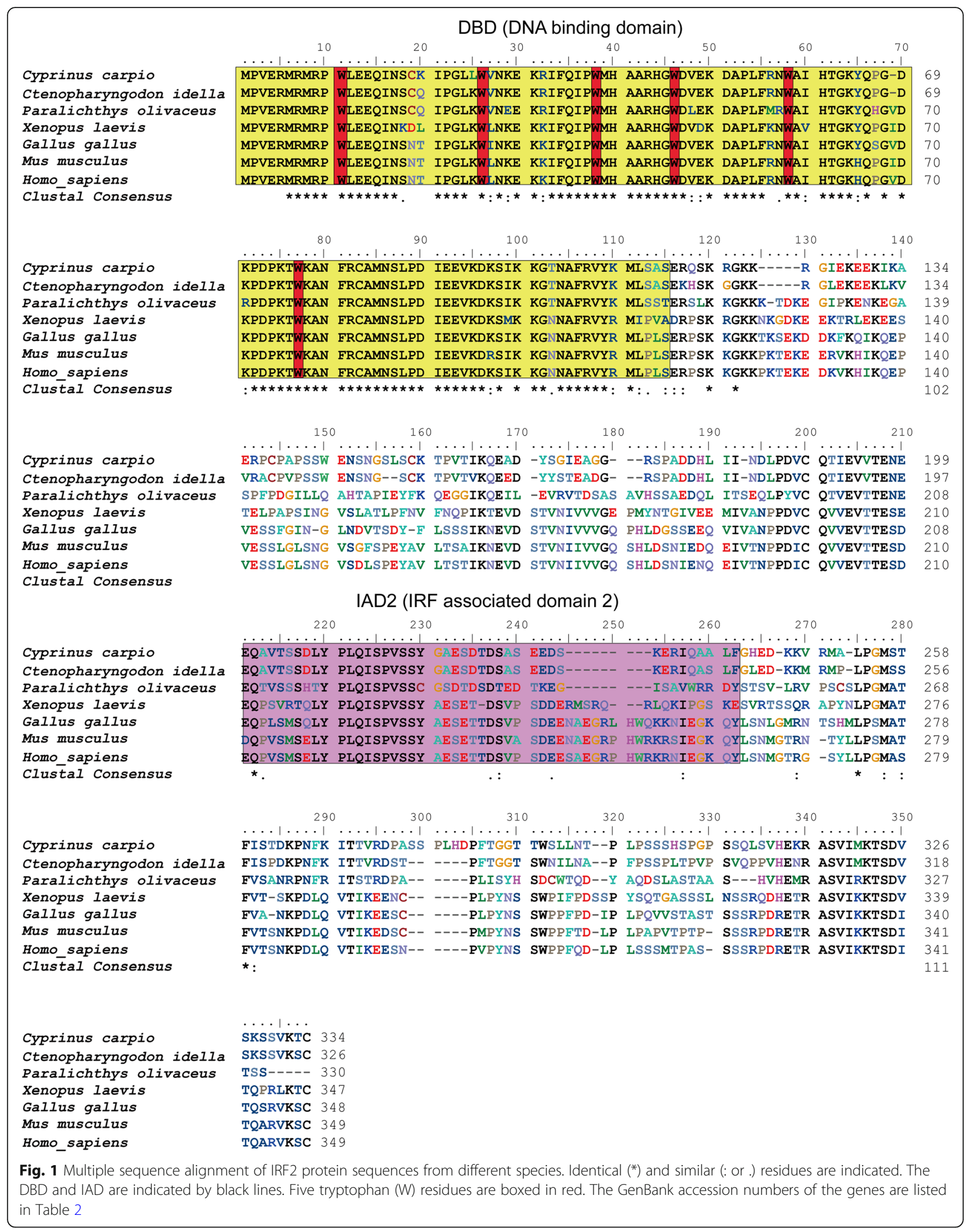




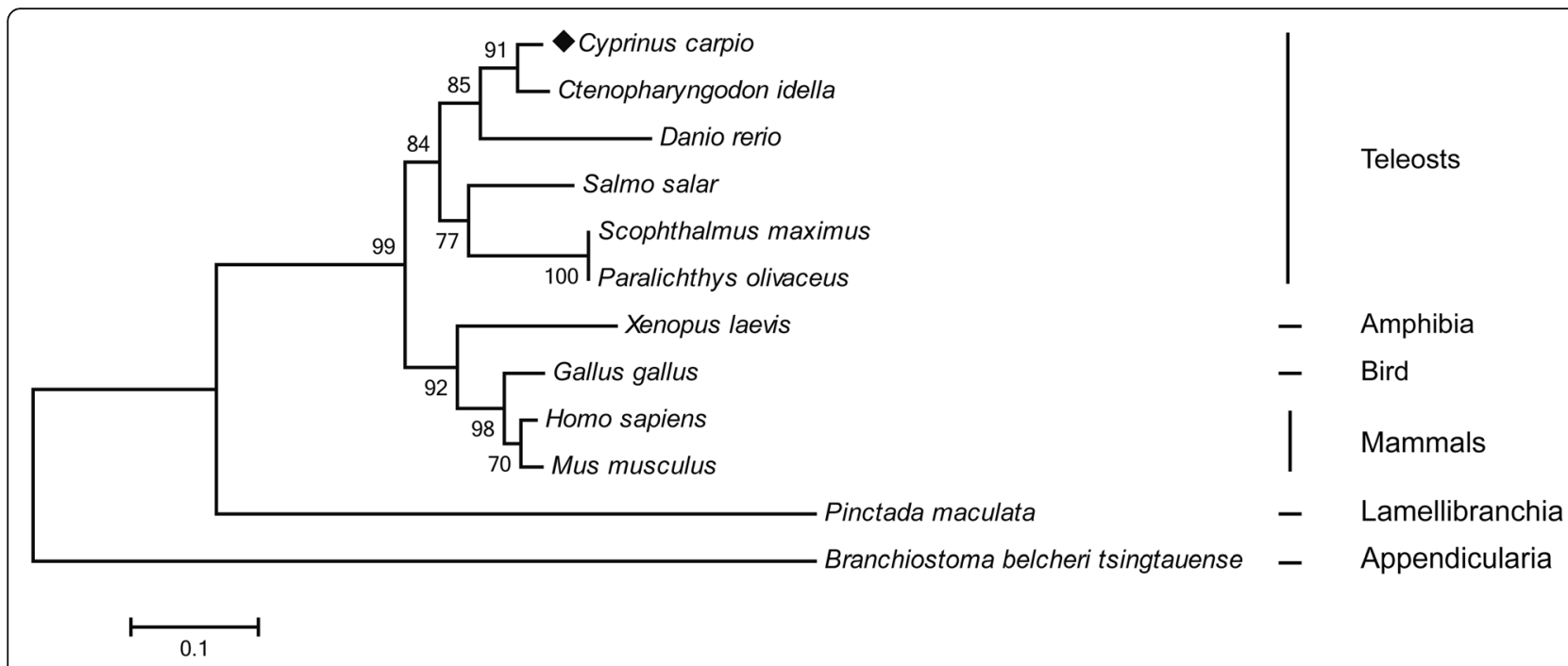

Fig. 2 Phylogenetic analysis of IRF2 protein sequences from different species. The phylogenetic tree was produced by the neighbour-joining method in MEGA 6.0. C. carpio IRF2 is marked with a solid diamond (•)

\section{The expression pattern of CcIRF2}

The expression of CcIRF2 in eleven tissues of healthy common carp was examined using Real-time PCR method, including the liver, spleen, head kidney, foregut, hindgut, gills, gonad, skin, muscle, buccal epithelium and brain. The results showed that CcIRF2 was expressed in all examined tissues, with higher expression in the gills, spleen and brain (Fig. 3).

\section{CcIRF2 expression in response to poly (I:C) and $A$. hydrophila stimulation in vivo}

To determine the immune function of $C c$ IRF2, CcIRF2 expression was examined in several immune-related tissues of common carp after viral or bacterial challenge. Upon poly (I:C) stimulation, the expression of CCIRF2 was increased and peaked at $3 \mathrm{hpi}$ in the liver (21.5fold), spleen (29.7-fold), head kidney (12.4-fold), foregut (26.3-fold) and hindgut (23.4-fold), and peaked at $6 \mathrm{hpi}$ in the skin (34.2-fold) (Fig. 4). In the fish treated with formalin-killed $A$. hydrophila, CcIRF2 expression was upregulated in the head kidney (4.5-fold) and hindgut (6.5-fold) at $6 \mathrm{hpi}$ and in the foregut (13.7-fold) at 24 hpi, while decreased in the spleen at 12 hpi (Fig. 5).

\section{Expression of CCIRF2 upon poly (I:C), LPS and PGN stimulation in vitro}

To determine the pathogen-associated molecular patterns (PAMPs) recognized by CcIRF2, the PBLs and HKLs of common carp were stimulated with poly (I:C), LPS, PGN or flagellin, and the expression of CcIRF2 was detected by Real-time PCR. The results showed that CCIRF2 expression in the PBLs was upregulated by poly (I:C) (4.7-fold), PGN (2.9-fold) and flagellin (1.6-fold) at $12 \mathrm{~h}$ but not changed by LPS (Fig. 6). In HKLs, CcIRF2

Table 2 Protein length and GenBank accession numbers of the IRF2 family members

\begin{tabular}{lll}
\hline Species & Protein length & GenBank accession No. \\
\hline Cyprinus carpio & 334 & MW559072 \\
Ctenopharyngodon idella & 326 & AFV99156 \\
Danio rerio & 314 & NP_001307117 \\
Scophthalmus maximus & 330 & AOV86412 \\
Paralichthys olivaceus & 330 & ADZ96216 \\
Salmo salar & 343 & ACI33066 \\
Xenopus laevis & 347 & NP_001088726 \\
Gallus gallus & 348 & NP_990527 \\
Mus musculus & 349 & AAl10667 \\
Homo sapiens & 349 & CAG3335 \\
Pinctada maculata & 350 & AFZ76969 \\
Branchiostoma belcheri tsingtauense & 338 & AJA02097 \\
\hline
\end{tabular}




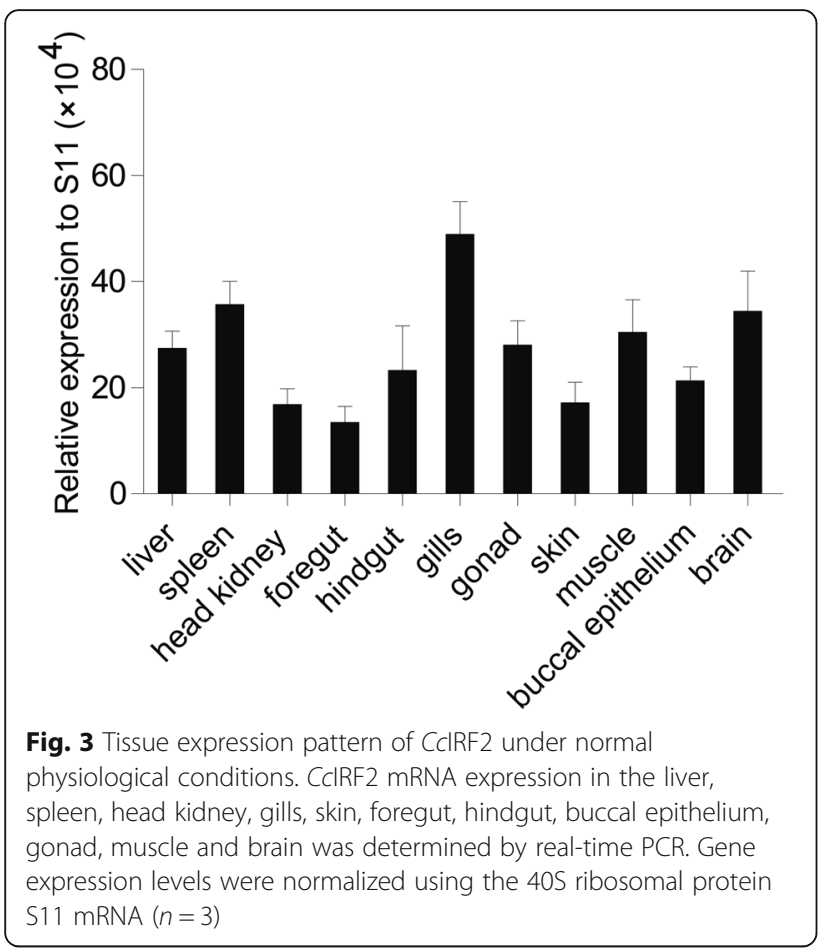

was induced by poly (I:C), LPS, PGN at $24 \mathrm{~h}$ (1.4-, 2.4-, and 2.6-fold) and flagellin at $12 \mathrm{~h}$ (1.2-fold) (Fig. 7).

\section{Regulatory role of CCIRF2 in the IFN signalling}

To investigate the role of CCIRF2 in the IFN signalling pathway, the gene expression of IFN, three ISGs (PKR, Viperin and ISG15) and IRF3 was detected after overexpression of CcIRF2 in EPC cells. The results showed that the expression level of these genes was significantly reduced, with 49, 54, 86, 66 and $15 \%$ of the level in control cells, respectively (Fig. 8).

\section{Regulation of NF-KB by CCIRF2}

To determine the role of $C c$ IRF2 in the activation of NF$\mathrm{\kappa B}$, dual-luciferase reporter assay was performed in 293 $\mathrm{T}$ cells. The results showed that MyD88 or TRIF could activate NF- $\mathrm{kB}$, and CcIRF2 enhanced MyD88- or TRIFinduced NF-kB activity (Fig. 9).

\section{Discussion}

IRFs, which were originally described as transcription factors induced by IFN, play a variety of roles in immune response, immune system development and cell growth $[4,34-36]$. With the development of the fishery economy, an increasing number of studies on IRFs in bony fish have been carried out. In the present study, the full-

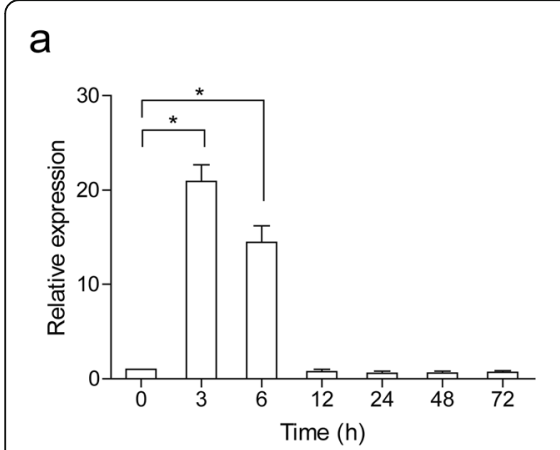

\section{b}

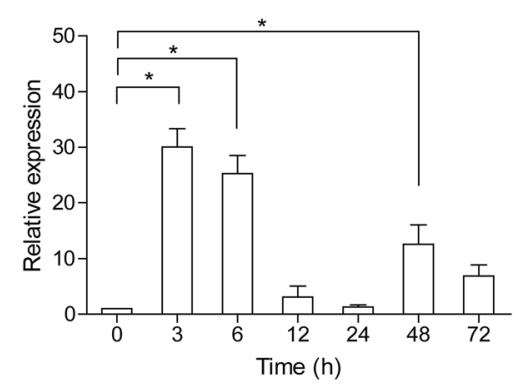

e

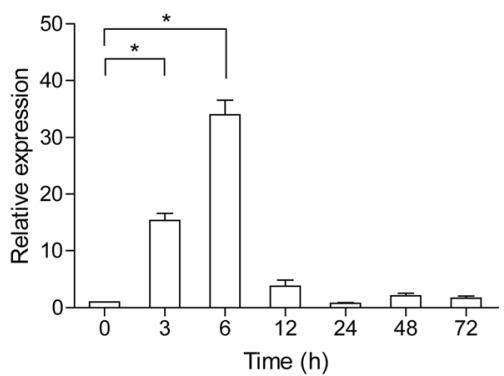

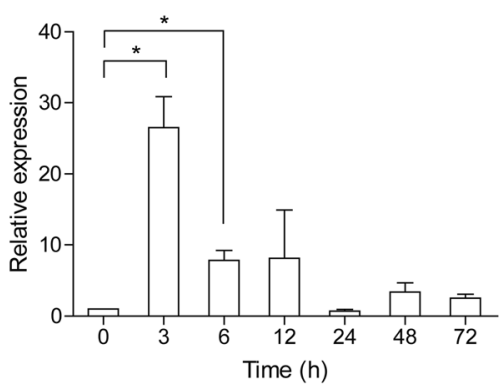

C

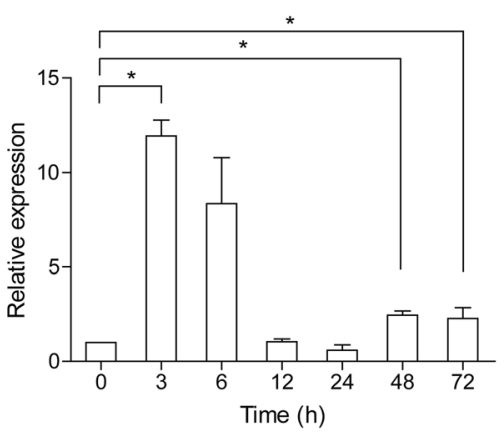

f

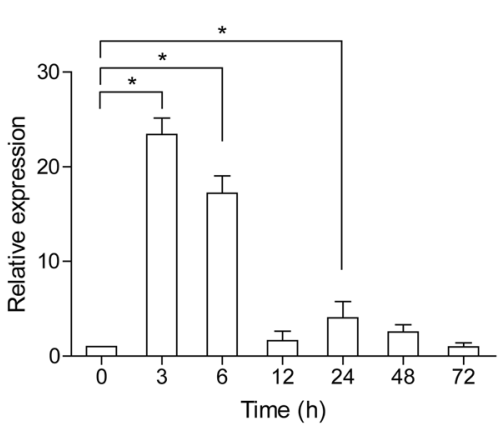

Fig. 4 Expression analysis of CCIRF2 in response to poly (I:C) challenge in vivo. Total RNA was extracted from the liver (a), spleen (b), head kidney (c), skin (d), foregut (e) and hindgut (f) at 0 (as a control), 3, 6, 12, 24, 48 and 72 hpi for real-time PCR. Expression was normalized using the 40S ribosomal protein $\mathrm{S} 11\left(\mathrm{n}=3\right.$, mean $\left.\pm \mathrm{SD},{ }^{*} P<0.05\right)$ 


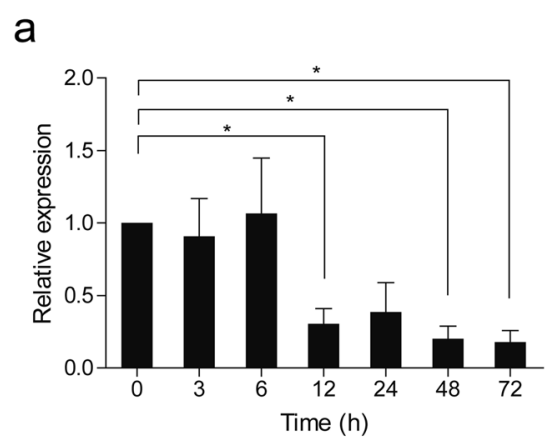

C

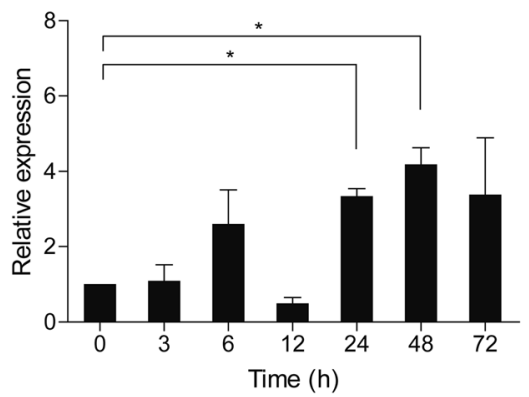

b

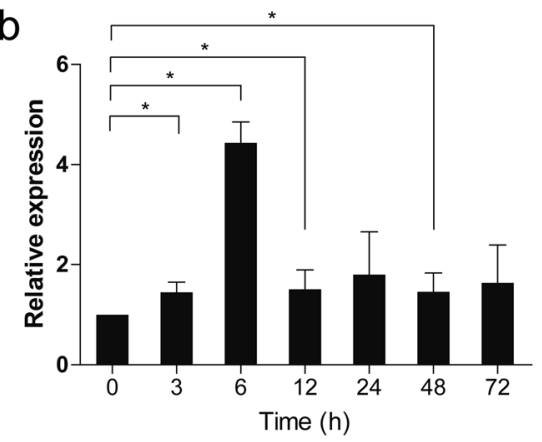

d

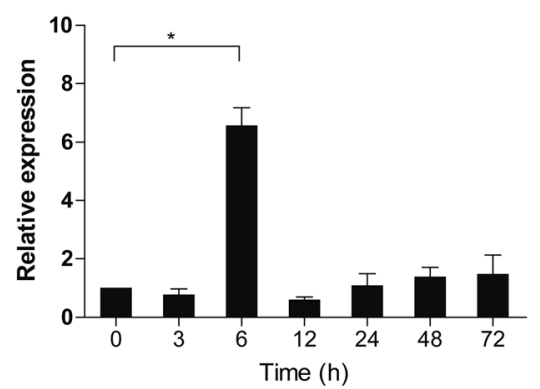

Fig. 5 Expression analysis of CIRF2 in response to A. hydrophila challenge in vivo. Total RNA was extracted from the spleen (a), head kidney (b), foregut (c) and hindgut (d) tissues at 0 (as a control), 3, 6, 12, 24, 48 and 72 hpi for real-time PCR. The expression was normalized using that of the $40 \mathrm{~S}$ ribosomal protein $\mathrm{S} 11\left(\mathrm{n}=3\right.$, mean $\left.\pm \mathrm{SD},{ }^{*} P<0.05\right)$

a

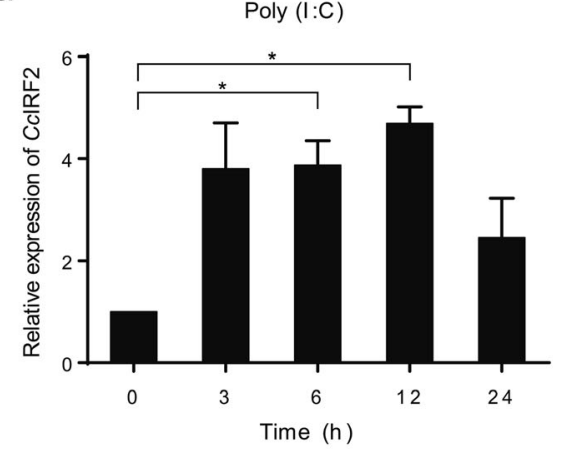

C

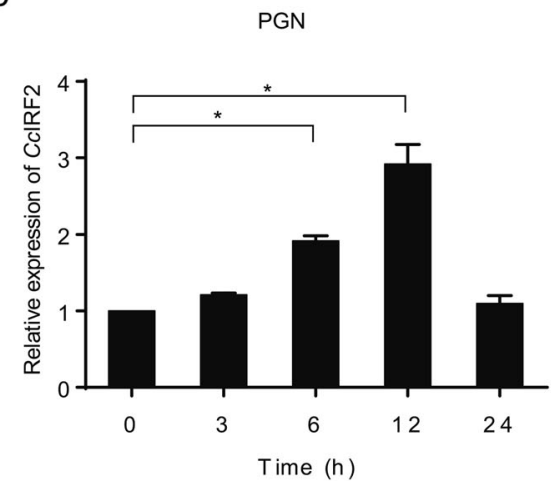

b

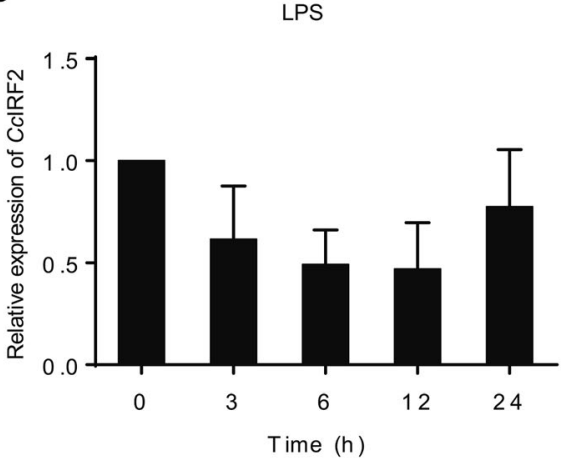

d

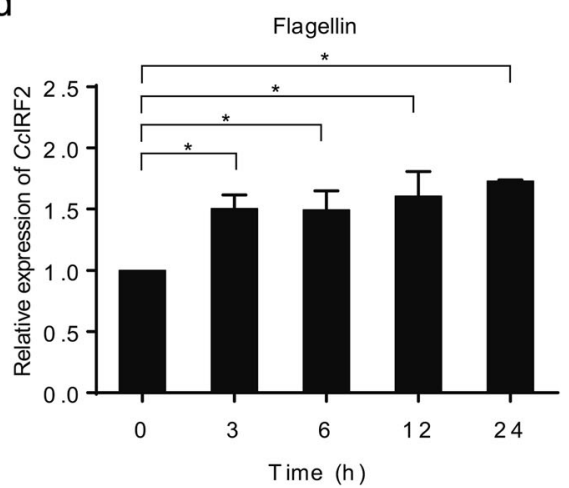

Fig. 6 Expression levels of CIRF2 in PBLs upon different stimulation. Expression of CCIRF2 in the PBLs induced by poly (I:C) (a), LPS (b), PGN (c) or Flagellin (d). The expression levels were normalized using the $40 \mathrm{~S}$ ribosomal protein S11 (mean $\pm \mathrm{SD},{ }^{*} P<0.05$ ) 

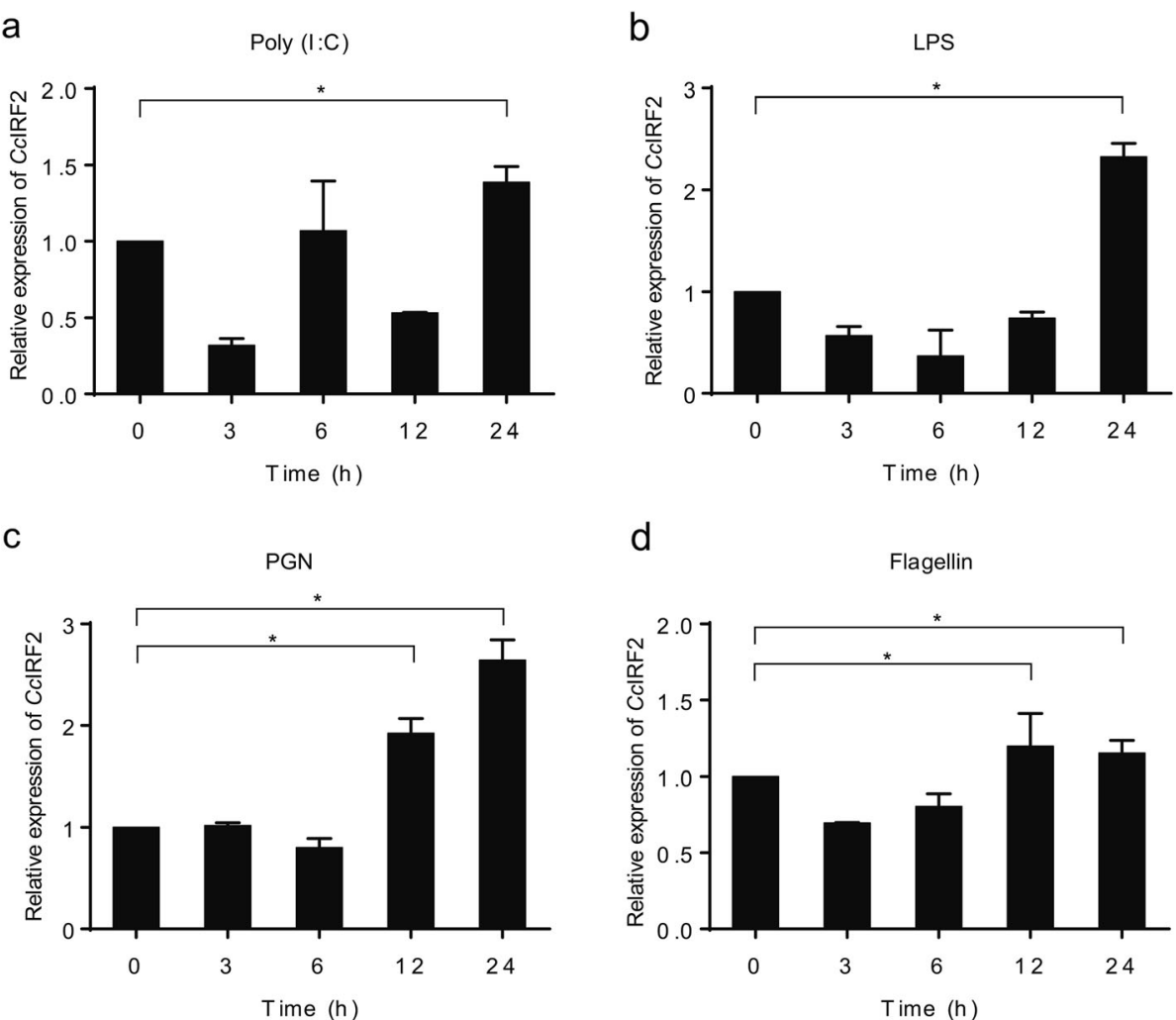

Fig. 7 Expression levels of CCIRF2 in HKLs upon different stimulation. Expression of CCIRF2 in the HKLs induced by poly (l:C) (a), LPS (b), PGN (c) or Flagellin (d). The expression levels were normalized using the $40 \mathrm{~S}$ ribosomal protein S11 (mean $\pm \mathrm{SD},{ }^{*} P<0.05$ )
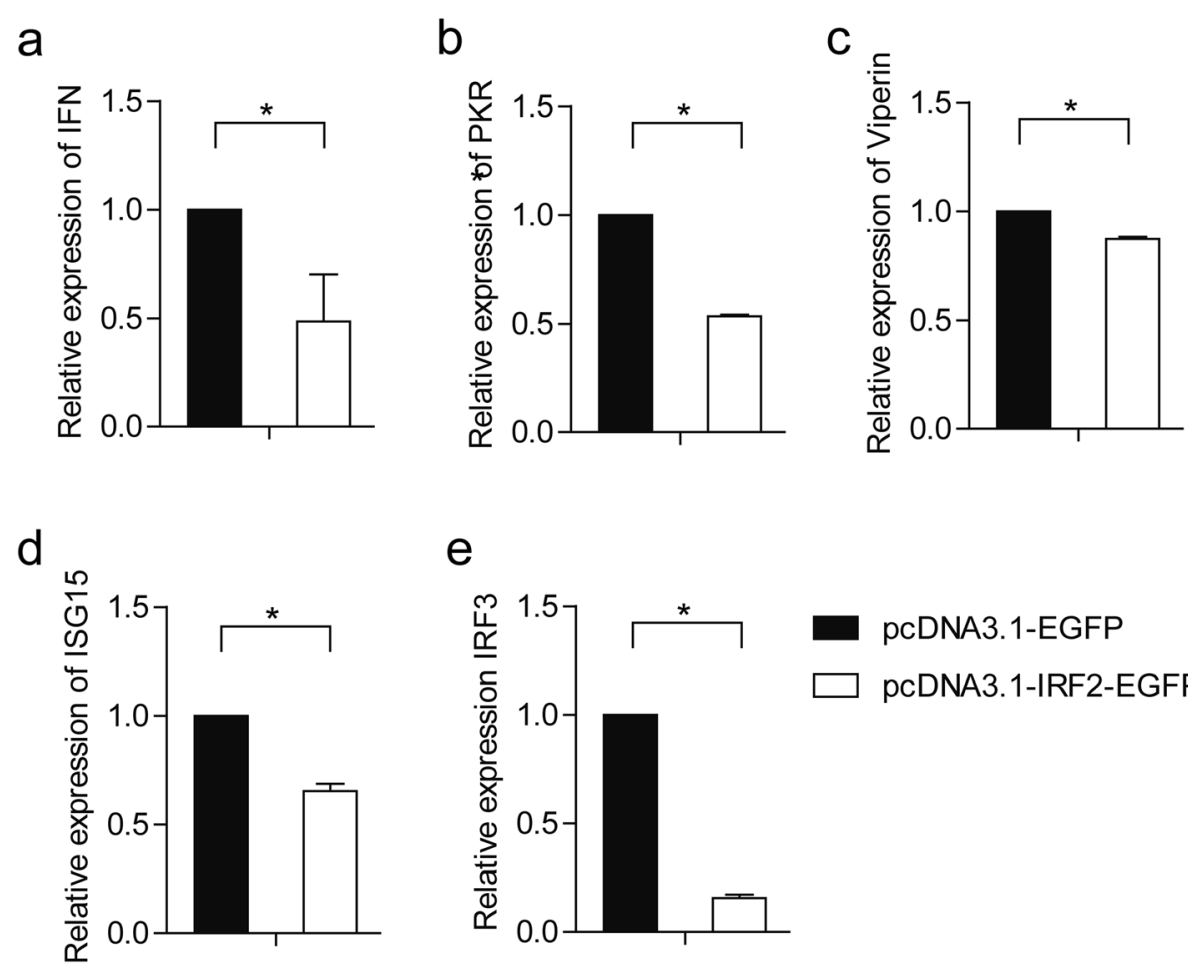

Fig. 8 Effect of CCIRF2 overexpression on expression of the IFN (a), PKR (b), Viperin (c), ISG15 (d) and IRF3 (e) genes in EPC cells. The expression levels were normalized to $\beta$-actin (mean $\pm S D,{ }^{*} P<0.05$ ) 


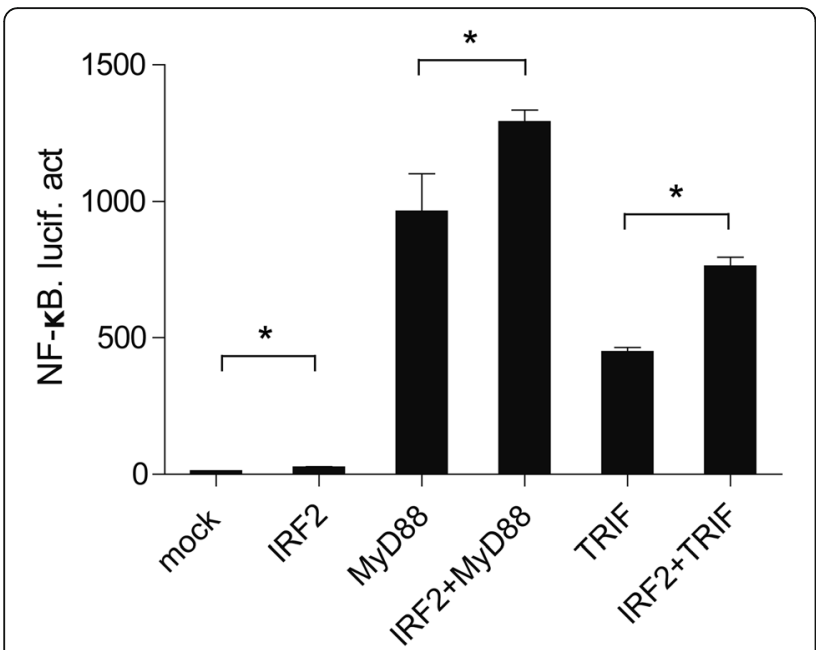

Fig. 9 IRF2 positively regulates the NF-kB pathway through MyD88 and TRIF. 293 T cells were cotransfected with the NF-KB reporter gene and CCIRF2 and MyD88/TRIF expression plasmids. Luciferase activity was measured after $48 \mathrm{~h}$ and determined against Renilla luciferase activity (mean $\pm \mathrm{SD},{ }^{*} P<0.05$ )

length CcIRF2 cDNA was cloned from common carp, which encodes 334 amino acid residues. Notably, IRF2 encodes 349 amino acid residues in human and mouse, 348 in chicken and 347 in xenopus, but fewer than 345 in fish, reflecting the important role of IRF2 in the process of biological evolution and possible differences in protein function of IRF2 from different species.

Both mammalian and fish IRFs contain a DBD in the $\mathrm{N}$-terminal region, which is responsible for binding the same ISRE/IRF-E sequences on target genes [37]. The CcIRF2 protein sequence was compared with that from pearl oyster, amphioxus, African clawed frog, chicken, mouse and human. The results showed that the DBD was relatively conserved, and the DBD in all species except amphioxus contained six tryptophan residues, suggesting that the function of the IRF2 molecule may be relatively evolutionarily conserved. There are two types of IRF C-termini: IAD1 was originally found in IRF8 and is present in all members of the IRF family except IRF1 and IRF2, while IAD2 exists in only IRF1 and IRF2 [38]. In the present study, the $\mathrm{C}$-terminus of $C \mathrm{IRF} 2$ contains the IAD2 domain.

The known IRF2 protein sequences from different species were used to construct an evolutionary tree using the neighbour-joining method. In the tree, IRF2s of teleosts, amphibia, bird and mammals are on a branch, while IRF2s of lamellibranchia and appendicularia are separate. The 11 members of the fish IRFs family are divided into four clades: the IRF1 subfamily, consisting of IRF1, IRF2 and IRF11; the IRF3 subfamily, consisting of IRF3 and IRF7; the IRF4 subfamily, consisting of IRF4, IRF8, IRF9 and IRF10; and the IRF5 subfamily, consisting of IRF5 and IRF6. CcIRF2 is closely related to grass carp in the branch containing fish species, which belongs to the IRF1 subfamily.

IRF2 is widely expressed in a variety of tissues in bony fish, such as E. coioides and O. mykiss $[6,10]$. In the present study, the expression pattern of CcIRF2 in 11 tissues of healthy common carp was investigated, which was expressed in all tissues, with higher expression level in the gills, spleen and brain. Concordant with these results, the expression of IRF2 is highest in the gills or spleen of $P$. spathula, $M$. amblycephala, $C$. argus and $C$. idella $[8,12,15]$. In fish, the spleen and gills are important systemic and mucosal immune organs, respectively, and play a key defensive role against pathogen invasion, suggesting that CcIRF2 plays an important role in the immune system of fish. Unexpectedly, the expression level of IRF2 in the brain of common carp was also high, implying that IRF2 may be involved in regulating the nervous system of fish.

The previous studies in fish have shown that IRF2 can be induced by poly (I:C), including mandarin fish, paddlefish, rainbow trout and snakehead $[6-8,12]$, and the expression level of IRF2 in the liver, spleen and head kidney of half-smooth tongue sole was also significantly increased after viral stimulation [39]. In the present study, after poly (I:C) stimulation, the expression of CcIRF2 in all tissues increased and peaked at $3 \mathrm{~h}$ or $6 \mathrm{~h}$, and the expression of CCIRF2 in the skin and spleen increased to the maximum level, suggesting that IRF2 may play an important role in the early immune response of common carp to viruses. After stimulation by A. hydrophila, the expression of CcIRF2 in the head kidney, foregut and hindgut was increased, but significantly decreased in the spleen. Similar to the results, after stimulation with $A$. hydrophila, the expression of IRF2 was increased in the spleen and head kidney but significantly decreased in the gills and intestines of bluntsnout bream. Therefore, the antibacterial immune process in which IRF2 is involved may be tissue-specific.

Similar to the in vivo results, poly (I:C) induced an increase in CcIRF2 expression in PBLs and HKLs. However, there was no significant change in CcIRF2 expression in PBLs after LPS stimulation. Studies in mammals have shown that LPS can induce the expression of IRF genes in B cells, $T$ cells, macrophages and dendritic cells $[40,41]$. However, fish can resist the toxic effects of LPS [42], and lack costimulatory molecules (such as MyD2 and CD14) produced by TLR4 during LPS-induced immune activation [43]. Therefore, the unchanged expression of CCIRF2 after LPS stimulation may be due to the different mechanism of LPS recognition between fish and mammals.

Mammalian IRF2 is unrelated to the production of IFN but is involved in the transcriptional regulation of 
downstream genes such as histone H4, IL-7, IL-12, iNOS and MHC class I molecules [44-48]. The previous studies have shown that mammalian IRF2 plays a role in inhibiting transcriptional regulation due to its competition with IRF1 [49], and amphioxus IRF2 can compete with other IRFs for the ISRE-binding site in the nucleus, thus IRF2 is considered a negative regulator of the transcription process [50]. In this study, the overexpression of IRF2 in common carp inhibited the expression of IFN, PKR, Viperin, ISG15 and IRF3 in EPC cells, so CcIRF2 may also negatively regulate the expression of IFN and related factors. However, the dual-luciferase reporter assay showed that CCIRF2 activated the NF- $\kappa B$ signalling pathway and promoted both MyD88-mediated and TRIF-mediated NF- $\mathrm{kB}$ production. Mammalian IRF2 was reported to regulate NF- $\kappa B$ activity by regulating the subcellular localization of NF- $\mathrm{KB}$ [51], and IRF2 in pearl oyster can also activate the NF- $\mathrm{kB}$ signalling pathways [52]. Thus, IRF2 belongs to a class of multifunctional transcription factors whose specific roles in transcriptional inhibition or activation depend on cell type and inflammatory state $[4,53,54]$.

\section{Conclusions}

In the present study, the full-length cDNA of the IRF2 gene was identified from common carp, and its effects on defence against pathogen invasion and regulation of the IFN response were investigated in vivo and in vitro. The results indicate that $C$ IRF2 participated in antiviral and antibacterial immunity and negatively regulated the IFN response, which provide a new insight into the regulation of IFN system in common carp, and are helpful for the prevention and control of infectious diseases in carp farming.

\section{Abbreviations \\ IFN: interferon; IRF: interferon regulatory factor; ISG: IFN-stimulated gene; DBD: DNA-binding domain; NLS: nuclear localization signal; IAD: IRF associated domain; poly (I:C): polyinosinic:polycytidylic acid; LPS: lipopolysaccharide; EPC: epithelioma papulosum cyprinid; RACE: rapid amplification of the CDNA ends; SMART: simple modular architecture research tool; PBL: peripheral blood leucocyte; HKL: head kidney leukocyte; PGN: peptidoglycan; ORF: open reading frame; ANOVA: one-way analysis of variance; UTR: untranslated region; hpi: hour post injection; ISRE: IFN stimulating response element; IRF-E: IRF regulatory element}

\section{Acknowledgments}

Not applicable.

\section{Authors' contributions}

H.L. and G.Y. conceived and designed the experiments. X.C., Y.Z., R.L., L.Z. and F.Z. performed the experiments. S.S. and L.A. analyzed the data. H.L. and X.C. wrote the paper. All authors reviewed the manuscript.

\section{Funding}

This work was supported by the National Key R\&D Program of China (2018YFD0900302-8), the National Natural Science Foundation of China (32002419, 31972828). The funders were not involved in the study design; collection, analysis and interpretation of the data; or in writing the manuscript.

\section{Availability of data and materials}

The dataset supporting the conclusions of this article is available in the GenBank (https://www.ncbi.nlm.nih.gov/nuccore/MW559072) and the accession number is MW559072.

\section{Declarations}

Ethics approval and consent to participate

The protocol was approved by the Animal Experimental Ethics Committee of Shandong Normal University, and all methods were performed in accordance with the relevant guidelines and regulations. The study was carried out in compliance with the ARRIVE guidelines.

Consent for publication

Not Applicable.

\section{Competing interests}

The authors declare that they have no competing interests.

\section{Author details}

${ }^{1}$ Shandong Provincial Key Laboratory of Animal Resistance Biology, College of Life Sciences, Shandong Normal University, No. 88 East Wenhua Road, Jinan 250014, China. ${ }^{2}$ College of Fisheries and Life Science, Hainan Tropical Ocean University, No. 1 Yucai Road, Sanya 572022, China. ${ }^{3}$ Jinan

Eco-environmental Monitoring Center of Shandong Province, No. 17199 Lvyou Road, Jinan 250101, China.

Received: 8 June 2021 Accepted: 2 September 2021

Published online: 09 September 2021

\section{References}

1. Mamane Y, Heylbroeck C, Genin P, Algarte M, Servant MJ, LePage C, et al. Interferon regulatory factors: the next generation. Gene. 1999;237(1):1-14. https://doi.org/10.1016/S0378-1119(99)00262-0.

2. Nguyen $\mathrm{H}$, Hiscott J, Pitha PM. The growing family of interferon regulatory factors. Cytokine Growth Factor Rev. 1997:8(4):293-312. https://doi.org/10.1 016/S1359-6101(97)00019-1.

3. Bathige SD, Whang I, Umasuthan N, Lim BS, Park MA, Kim E, et al. Interferon regulatory factors 4 and 8 in rock bream, Oplegnathus fasciatus: structural and expressional evidence for their antimicrobial role in teleosts. Fish Shellfish Immunol. 2012;33(4):857-71. https://doi.org/10.1016/j.fsi.2012.07.01 7.

4. Tamura T, Yanai H, Savitsky D, Taniguchi T. The IRF family transcription factors in immunity and oncogenesis. Annu Rev Immunol. 2008;26(1):53584. https://doi.org/10.1146/annurev.immunol.26.021607.090400.

5. Zhu KC, Guo HY, Zhang N, Guo L, Liu BS, Jiang SG, et al. Functional characterization of interferon regulatory factor 2 and its role in the transcription of interferon a3 in golden pompano Trachinotus ovatus (Linnaeus 1758). Fish Shellfish Immunol. 2019;93:90-8. https://doi.org/10.101 6/j.fsi.2019.07.045.

6. Collet B, Hovens GC, Mazzoni D, Hirono I, Aoki T, Secombes CJ. Cloning and expression analysis of rainbow trout Oncorhynchus mykiss interferon regulatory factor 1 and 2 (IRF-1 and IRF-2). Dev Comp Immunol. 2003;27(2): 111-26. https://doi.org/10.1016/S0145-305X(02)00072-1.

7. Sun B, Chang M, Chen D, Nie P. Gene structure and transcription of IRF-2 in the mandarin fish Siniperca chuatsi with the finding of alternative transcripts and microsatellite in the coding region. Immunogenetics. 2006; 58(9):774-84. https://doi.org/10.1007/s00251-006-0129-y.

8. Jia W, Guo Q. Gene structures and promoter characteristics of interferon regulatory factor 1 (IRF-1), IRF-2 and IRF-7 from snakehead Channa argus. Mol Immunol. 2008;45(8):2419-28. https://doi.org/10.1016/j.molimm.2007.11. 011.

9. Huang B, Qi ZT, Xu Z, Nie P. Global characterization of interferon regulatory factor (IRF) genes in vertebrates: glimpse of the diversification in evolution. BMC Immunol. 2010;11(1):22. https://doi.org/10.1186/1471-2172-11-22.

10. Shi $Y$, Zhao Z, Yin JK, Zhu XP, Chen KC, Pan DB, et al. Interferon regulatory factor-2 in orange-spotted grouper (Epinephelus coioides): gene, inductive expression pattern and subcellular localization. Comp Biochem Physiol B Biochem Mol Biol. 2010;155(2):110-7. https://doi.org/10.1016/j.cbpb.2009.10. 008. 
11. Bergan V, Kileng O, Sun B, Robertsen B. Regulation and function of interferon regulatory factors of Atlantic salmon. Mol Immunol. 2010;47(1112):2005-14. https://doi.org/10.1016/j.molimm.2010.04.015.

12. Xiaoni G, Zhuo C, Xuzhen W, Dengqiang W, Xinwen C. Molecular cloning and characterization of interferon regulatory factor 1 (IRF-1), IRF-2 and IRF-5 in the chondrostean paddlefish Polyodon spathula and their phylogenetic importance in the Osteichthyes. Dev Comp Immunol. 2012;36(1):74-84. https://doi.org/10.1016/j.dci.2011.06.003.

13. Shu C, Sun Y, Xu T. Molecular characterization of three IRF1 subfamily members reveals evolutionary significance of IRF11 in miiuy croaker. Dev Comp Immunol. 2015;53(2):385-91. https://doi.org/10.1016/j.dci.2015.07.009.

14. Gu M, Lin G, Lai Q, Zhong B, Liu Y, Mi Y, et al. Ctenopharyngodon idella IRF2 plays an antagonistic role to IRF1 in transcriptional regulation of IFN and ISG genes. Dev Comp Immunol. 2015;49(1):103-12. https://doi.org/10.1 016/j.dci.2014.11.014

15. Zhan FB, Liu H, Lai RF, Jakovlic I, Wang WM. Expression and functional characterization of interferon regulatory factors (irf2, irf7 and irf9) in the blunt snout bream (Megalobrama amblycephala). Dev Comp Immunol. 2017;67:239-48. https://doi.org/10.1016/j.dci.2016.09.014.

16. Inkpen SM, Solbakken MH, Jentoft S, Eslamloo K, Rise ML. Full characterization and transcript expression profiling of the interferon regulatory factor (IRF) gene family in Atlantic cod (Gadus morhua). Dev Comp Immunol. 2019;98:166-80. https://doi.org/10.1016/j.dci.2019.03.015.

17. Li Y, Esain V, Teng L, Xu J, Kwan W, Frost IM, et al. Inflammatory signaling regulates embryonic hematopoietic stem and progenitor cell production. Genes Dev. 2014;28(23):2597-612. https://doi.org/10.1101/gad.253302.114.

18. Zhu KC, Liu BS, Zhang N, Guo HY, Guo L, Jiang SG, et al. Interferon regulatory factor 2 plays a positive role in interferon gamma expression in golden pompano, Trachinotus ovatus (Linnaeus 1758). Fish Shellfish Immunol. 2020;96:107-13. https://doi.org/10.1016/j.fsi.2019.12.006.

19. Chen X, Guan Y, Li K, Luo T, Mu Y, Chen X. IRF1 and IRF2 act as positive regulators in antiviral response of large yellow croaker (Larimichthys crocea) by induction of distinct subgroups of type I IFNs. Dev Comp Immunol. 2021;118:103996. https://doi.org/10.1016/j.dci.2021.103996.

20. Shan S, Qi C, Zhu Y, Li H, An L, Yang G. Expression profile of carp IFN correlate with the up-regulation of interferon regulatory factor-1 (IRF-1) in vivo and in vitro: the pivotal molecules in antiviral defense. Fish Shellfish Immunol. 2016;52:94-102. https://doi.org/10.1016/j.fsi.2016.03.019.

21. Feng $H$, Liu $H$, Kong $R$, Wang $L$, Wang $Y, H u$ W, et al. Expression profiles of carp IRF-3/-7 correlate with the up-regulation of RIG-I/MAVS/TRAF3/TBK1, four pivotal molecules in RIG-I signaling pathway. Fish Shellfish Immunol. 2011;30(4-5):1159-69. https://doi.org/10.1016/j.fsi.2011.03.002.

22. Zhu Y, Qi C, Shan S, Zhang F, Li H, An L, Yang G: Characterization of common carp (Cyprinus carpio L.) interferon regulatory factor 5 (IRF5) and its expression in response to viral and bacterial challenges. BMC Vet Res 2016, 12(1):127.

23. Zhu Y, Shan S, Feng H, Jiang L, An L, Yang G, et al. Molecular characterization and functional analysis of interferon regulatory factor 9 (irf9) in common carp Cyprinus carpio: a pivotal molecule in the Ifn response against pathogens. J Fish Biol. 2019;95(2):510-9. https://doi.org/1 $0.1111 /$ jfb. 14000 .

24. Zhu Y, Shan S, Zhao H, Liu R, Wang H, Chen X, Yang G, Li H: Identification of an IRF10 gene in common carp (Cyprinus carpio L.) and analysis of its function in the antiviral and antibacterial immune response. BMC Vet Res 2020, 16(1):450.

25. Wang QC, Ji W, Xu Z. Current use and development of fish vaccines in China. Fish Shellfish Immun. 2020;96:223-34. https://doi.org/10.1016/j.fsi.201 9.12.010.

26. Wang JL, Meng XL, Lu RH, Wu C, Luo YT, Yan X, et al. Effects of Rehmannia glutinosa on growth performance, immunological parameters and disease resistance to Aeromonas hydrophila in common carp (Cyprinus carpio L.). Aquaculture. 2015;435:293-300. https://doi.org/10.1016/j.aquaculture.2014.1 0.004

27. Maji S, Mali P, Joardar SN. Immunoreactive antigens of the outer membrane protein of Aeromonas hydrophila, isolated from goldfish, Carassius auratus (Linn.). Fish Shellfish Immun. 2006;20(4):462-73. https://doi.org/10.1016/j.fsi.2 005.06.003.

28. Zhang XT, Zhang GR, Shi ZC, Yuan YJ, Zheng H, Lin L, et al. Expression analysis of nine toll-like receptors in yellow catfish (Pelteobagrus fulvidraco) responding to Aeromonas hydrophila challenge. Fish Shellfish Immun. 2017; 63:384-93. https://doi.org/10.1016/j.fsi.2017.02.021.
29. Yun S, Jun JW, Giri SS, Kim HJ, Chi C, Kim SG, et al. Efficacy of PLGA microparticle-encapsulated formalin-killed Aeromonas hydrophila cells as a single-shot vaccine against a. hydrophila infection. Vaccine. 2017;35(32): 3959-65. https://doi.org/10.1016/j.vaccine.2017.06.005.

30. Tomas JM. The main Aeromonas pathogenic factors. ISRN Microbiol. 2012; 2012:256261-22. https://doi.org/10.5402/2012/256261.

31. Shan SJ, Liu DZ, Wang L, Zhu YY, Zhang FM, Li T, et al. Identification and expression analysis of irak1 gene in common carp Cyprinus carpio L.: indications for a role of antibacterial and antiviral immunity. J Fish Biol. 2015;87(2):241-55. https://doi.org/10.1111/jfb.12714.

32. Shan S, Wang L, Zhang F, Zhu Y, An L, Yang G: Characterization and expression analysis of Toll-interacting protein in common carp, Cyprinus carpio L., responding to bacterial and viral challenge. SpringerPlus 2016, 5: 639, 1, DOl: https://doi.org/10.1186/s40064-016-2293-3.

33. Zhu YY, Xing WX, Shan SJ, Zhang SQ, Li YQ, Li T, et al. Characterization and immune response expression of the rig-l-like receptor mda5 in common carp Cyprinus carpio. J Fish Biol. 2016;88(6):2188-202. https://doi.org/1 0.1111/jfb.12981.

34. Taniguchi T, Ogasawara K, Takaoka A, Tanaka N. IRF family of transcription factors as regulators of host defense. Annu Rev Immunol. 2001;19(1):623-55. https://doi.org/10.1146/annurev.immunol.19.1.623.

35. Barnes B, Lubyova B, Pitha PM. On the role of IRF in host defense. J Interferon Cytokine Res. 2002;22(1):59-71. https://doi.org/10.1089/107999002 753452665 .

36. Colonna M. TLR pathways and IFN-regulatory factors: to each its own. Eur J Immunol. 2007;37(2):306-9. https://doi.org/10.1002/eji.200637009.

37. Paun A, Pitha PM. The IRF family, revisited. Biochimie. 2007:89(6-7):744-53. https://doi.org/10.1016/j.biochi.2007.01.014.

38. Takaoka A, Tamura T, Taniguchi T. Interferon regulatory factor family of transcription factors and regulation of oncogenesis. Cancer Sci. 2008;99(3): 467-78. https://doi.org/10.1111/j.1349-7006.2007.00720.x.

39. Zhang J, Li YX, Hu YH. Molecular characterization and expression analysis of eleven interferon regulatory factors in half-smooth tongue sole, Cynoglossus semilaevis. Fish Shellfish Immunol. 2015;44(1):272-82. https:// doi.org/10.1016/j.fsi.2015.02.033.

40. Gauzzi MC, Purificato C, Conti L, Adorini L, Belardelli F, Gessani S. IRF-4 expression in the human myeloid lineage: up-regulation during dendritic cell differentiation and inhibition by 1alpha,25-dihydroxyvitamin D3. J Leukoc Biol. 2005;77(6):944-7. https://doi.org/10.1189/jlb.0205090.

41. Gautier G, Humbert M, Deauvieau F, Scuiller M, Hiscott J, Bates EE, et al. A type I interferon autocrine-paracrine loop is involved in toll-like receptorinduced interleukin-12p70 secretion by dendritic cells. J Exp Med. 2005; 201(9):1435-46. https://doi.org/10.1084/jem.20041964.

42. Rodkhum C, Hirono I, Stork M, Di Lorenzo M, Crosa JH, Aoki T. Putative virulence-related genes in vibrio anguillarum identified by random genome sequencing. J Fish Dis. 2006;29(3):157-66. https://doi.org/10.1111/j.1365-2 761.2006.00692.x

43. Sepulcre MP, Alcaraz-Perez F, Lopez-Munoz A, Roca FJ, Meseguer J, Cayuela $M L$, et al. Evolution of lipopolysaccharide (LPS) recognition and signaling: fish TLR4 does not recognize LPS and negatively regulates NF-kappaB activation. J Immunol. 2009;182(4):1836-45. https://doi.org/10.4049/ jimmunol.0801755.

44. Driggers PH, Ennist DL, Gleason SL, Mak WH, Marks MS, Levi BZ, et al. An interferon gamma-regulated protein that binds the interferon-inducible enhancer element of major histocompatibility complex class I genes. Proc Natl Acad Sci U S A. 1990;87(10):3743-7. https://doi.org/10.1073/pnas.87.10.3743.

45. Oshima S, Nakamura T, Namiki S, Okada E, Tsuchiya K, Okamoto R, et al. Interferon regulatory factor 1 (IRF-1) and IRF-2 distinctively up-regulate gene expression and production of interleukin-7 in human intestinal epithelial cells. Mol Cell Biol. 2004;24(14):6298-310. https://doi.org/10.1128/MCB.24.14. 6298-6310.2004.

46. Salkowski CA, Barber SA, Detore GR, Vogel SN. Differential dysregulation of nitric oxide production in macrophages with targeted disruptions in IFN regulatory factor-1 and -2 genes. J Immunol. 1996;156(9):3107-10.

47. Salkowski CA, Kopydlowski K, Blanco J, Cody MJ, McNally R, Vogel SN. IL-12 is dysregulated in macrophages from IRF-1 and IRF-2 knockout mice. J Immunol. 1999;163(3):1529-36.

48. Vaughan PS, Aziz F, van Wijnen AJ, Wu S, Harada H, Taniguchi T, et al. Activation of a cell-cycle-regulated histone gene by the oncogenic transcription factor IRF-2. Nature. 1995;377(6547):362-5. https://doi.org/10.1 038/377362a0. 
49. Harada H, Fujita T, Miyamoto M, Kimura Y, Maruyama M, Furia A, et al. Structurally similar but functionally distinct factors, IRF-1 and IRF-2, bind to the same regulatory elements of IFN and IFN-inducible genes. Cell. 1989; 58(4):729-39. https://doi.org/10.1016/0092-8674(89)90107-4.

50. Yuan S, Zheng T, Li P, Yang R, Ruan J, Huang S, et al. Characterization of Amphioxus IFN regulatory factor family reveals an archaic signaling framework for innate immune response. J Immunol. 2015;195(12):5657-66. https://doi.org/10.4049/jimmunol.1501927.

51. Chae M, Kim K, Park SM, Jang IS, Seo T, Kim DM, et al. IRF-2 regulates NFkappaB activity by modulating the subcellular localization of NF-kappaB. Biochem Biophys Res Commun. 2008;370(3):519-24. https://doi.org/10.1016/ j.bbrc.2008.03.136.

52. Huang XD, Liu WG, Wang Q, Zhao M, Wu SZ, Guan YY, et al. Molecular characterization of interferon regulatory factor 2 (IRF-2) homolog in pearl oyster Pinctada fucata. Fish Shellfish Immunol. 2013;34(5):1279-86. https:// doi.org/10.1016/j.fsi.2013.02.003

53. Tanaka N, Kawakami T, Taniguchi T. Recognition DNA sequences of interferon regulatory factor 1 (IRF-1) and IRF-2, regulators of cell growth and the interferon system. Mol Cell Biol. 1993;13(8):4531-8. https://doi.org/10.112 8/mcb.13.8.4531-4538.1993.

54. Taniguchi T. IRF-1 and IRF-2 as regulators of the interferon system and cell growth. Indian J Biochem Biophys. 1995;32(5):235-9.

\section{Publisher's Note}

Springer Nature remains neutral with regard to jurisdictional claims in published maps and institutional affiliations.

Ready to submit your research? Choose BMC and benefit from:

- fast, convenient online submission

- thorough peer review by experienced researchers in your field

- rapid publication on acceptance

- support for research data, including large and complex data types

- gold Open Access which fosters wider collaboration and increased citations

- maximum visibility for your research: over $100 \mathrm{M}$ website views per year

At BMC, research is always in progress.

Learn more biomedcentral.com/submissions 